\title{
Influence of Surface Treatment of Fresh Concrete on its Resistance to Drying Shrinkage
}

\author{
Pavel Reiterman ${ }^{1}$ and Vendula Davidová ${ }^{2}$ \\ ${ }^{1}$ Czech Technical University in Prague, University Centre for Energy Efficient Buildings, Trinecka \\ 1024, 27343 Bustehrad, Czech Republic, pavel.reiterman@fsv.cvut.cz \\ ${ }^{2}$ Experimental Centre, Faculty of Civil Engineering, Czech Technical University in Prague (CTU), \\ Thákurova 7, 16629 Prague 6, Czech Republic, vendula.davidova@fsv.cvut.cz
}

\begin{abstract}
The volume changes of cement-based composites are significantly exhibited during the hardening process. Initial phases of the hardening are complemented by the expansion due to the heat evolution that is subsequently alternated by the shrinkage. Both could cause the crack initiation causing significant loss of the durability and service-life shortage. The present paper focuses on the experimental investigation of the surface treatment of fresh concrete, which is applied to prevent sudden loss of the moisture during a hardening process, especially during the concrete highway construction. The technology of concrete highway production is extremely costs demanding, but its efficiency is determined by the longer lifespan in comparison with the asphalt pavement. However, negative impacts of the drying shrinkage could significantly reduce the durability. The efficiency of used treatment was investigated in terms of restrained shrinkage tests, water adsorption and mechanical testing. In addition, there were studied two types of conventional Portland cement. Performed program confirmed great sense of the curing on the concrete durability; in addition, there was well illustrated the efficiency of the utilization of blended binder systems in the paper.
\end{abstract}

Keywords: Concrete Permeability, Drying Shrinkage, Surface Treatment.

\section{Introduction}

The concrete is the most used material for the construction of civil infrastructure worldwide. The fundamental part of the structural concrete is Portland cement, which exhibits hydraulic properties and sufficient mechanical and also durability performance. There is a number of various types of cements, that are based on Portland clinker, however these cement types were primarily developed for the specific applications (Aitcin, 2000). For example, blended systems are preferably used for massive structures for the reduction of total hydration heat and also volume changes (Lotenbach et al. 2011; Vinkler and Vítek, 2019). On the other hand, due to rapidly increasing price of human work there are currently preferred technologies limiting number of craftsmen on the construction site and approaches significantly accelerating the process of construction.

These technologies often lead to the supressing of specific technological steps, such as curing. Portland cement based concrete is hydraulic material, which is sensitive for a sudden loss of moisture during hydration. Surface treatments in form of thin films are applied to prevent the drying of concrete after its casting, because hardened mass of concrete significantly reduces its diffusivity. The quality of surface layer of concrete is crucial in relation to the durability, because this thin part of structure determine final resistance to the impact of external environment. The deterioration of the concrete "skin" during hardening is the most frequent 
reason of the damage during structure operation. Traditional exhibition of the problem in concrete surface layer is the presence of micro cracks or tendency to release dust particles. These failures of concrete surface subsequently lead to the increased transport of water, which significantly contributes to the gradual degradation of the structure (Reiterman et al., 2019; Holcapek et al., 2014). The ingress of deicers and freezing-thawing are the main mechanisms causing the degradation of concrete infrastructure (Glinicki et al., 2016). The effect of frost causes propagation of cracks and their depth, and deicers, mostly on the basis of chlorides, lead to the chemical corrosion of concrete, surface scaling and corrosion of the embedded steel rebars. Hence, the permeability of concrete surface has crucial sense in relation to the lifespan of concrete structures.

\section{Experimental Program}

Conducted experimental program was focused on the evaluation of the quality of concrete surface layer, of which properties were modified by the application of surface treatment to prevent sudden evaporation of the moisture. This technology is used during the production of concrete pavement by the roller, and also after production of continues concrete guardrails. This effect was studied on standard cement mortars with the fraction of sand to cement $3: 1$, water to cement ration was set to 0.45 . There were used two types of Portland clinker-based cements CEM I 42.5 (SC) and CEM II 32.2 B-S, of which properties are introduced in Table 1.
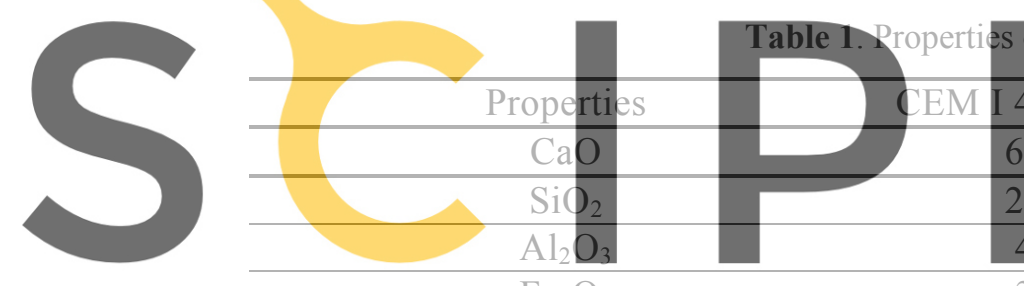

$\mathrm{Fe}_{2} \mathrm{O}_{3}$
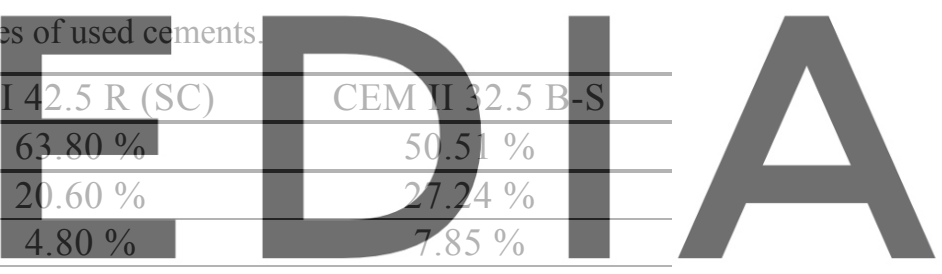

\begin{tabular}{|c|c|c|}
\hline $\mathrm{K}_{2} \mathrm{O}$ & $0.74 \%$ & $0.77 \%$ \\
\hline $\mathrm{NaO}$ & $0.20 \%$ & $0.36 \%$ \\
\hline LOI & $1.40 \%$ & $1.1 \%$ \\
\hline Blaine & $311 \mathrm{~m}^{2} / \mathrm{kg}$ & $345 \mathrm{~m}^{2} / \mathrm{kg}$ \\
\hline
\end{tabular}

CEM I 42.5 (SC) is a specific type of Portland cement, produced in Czech Republic, which is intended for the utilization during the construction of road pavement and transport structures. Its significant feature is low content of $\mathrm{C}_{3} \mathrm{~A}$ and lower value of specific surface by Blaine. CEM II 32.2 B-S performs cement with the content of blast furnace slag, which stands out from low hydration heat, low shrinkage and long-term evolution of mechanical properties.

Fresh mortars were prepared in laboratory mixer and sets of specimens were casted. Standard prismatic specimens $40 \times 40 \times 160 \mathrm{~mm}$ were used for the determination of mechanical properties in terms of EN 196-1.

Transport properties of cement mortars were studied using cylindrical specimens of height $50 \mathrm{~mm}$ and diameter $150 \mathrm{~mm}$. A half of these samples were approximately 5 minutes after casting sprayed by surface agent to prevent evaporation. A commercial product Novapor HV, 
on the basis of ethoxylated alcohol was used in the program. Recommended amount of the treatment is $200-250 \mathrm{~g} / \mathrm{m}^{2}$. A second half of samples served as a reference set. These cylindrical specimens were subsequently weighed to monitor the loss of the moisture in time. After 28 days were cylinders extracted from plastic molds, sealed on the lateral sides and they were subjected to the determination of water adsorption test to assess the surface quality. Samples were partially wetted into the water basin with downward orientation and the gradual ingress of water mass was gravimetrically determined.

The loss of the moisture has direct influence on the values of the shrinkage, respectively to drying shrinkage, because ultimate level of shrinkage is affected also by the mineralogy and properties of used cements (Davidova and Reiterman, 2020; Deboucha et al., 2017; Nili and Ehsani, 2015). The dimensions of the ring are rather small, which enables quicker testing of mortar susceptibility to cracking. The method consists of casting a ring of mortar around a polished ring of steel and its following spontaneous hardening and drying under normal laboratory conditions. As the mortar attempts to contract against the restraint of steel ring, tensile stress develops in the mortar ring and it might crack. The crack initiation is usually monitored visually in selected time intervals. The mortar rings had cross-section $25 \mathrm{~mm}$ in radial thickness and $38 \mathrm{~mm}$ deep. With respect to nature of testing, fresh surface of a half of samples was treated by surface agent as well. Subsequent drying was conducted only through upper part of the ring, because the rings were kept in the mold during to test to prevent drying of the part, which cannot be treated.
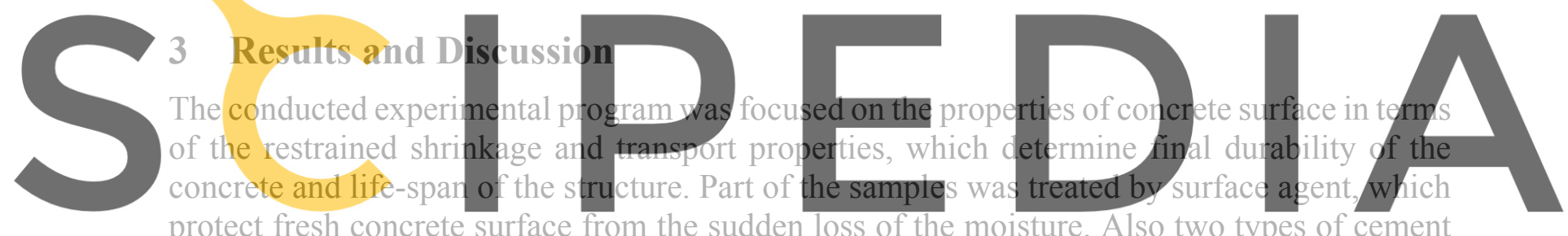
protect fresh concrete surface from the sudden loss of the moisture. Also two types of cement

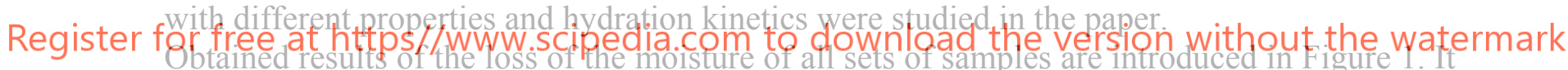

is evident, that reference and treated samples are very sensitive for the evaporation of the water during initial hours of the hardening, where the effect of the treatment is very low. However, after the setting, when solid structure occurs, the studied process is controlled by the diffusion, what well declare obtained curves. There is evident contribution of used treatment from the long-term point of view. There is also visible difference in the efficiency for single cement types. In case of blended system was the improvement over $20 \%$, however in case of pure Portland cement is the improvement only just about $5 \%$. It is caused by the different hydration kinetics; rapid setting is more suitable.

Determination of mechanical properties confirmed expected slower development of mechanical performance in case of blended cement. Detailed values are introduced in Table 2. On the other hand, values of compressive strength after 28 days of curing are relatively high. Nevertheless, high kinetics of the setting usually lead to the cracking. Conducted tests of restrained shrinkage did not confirmed this hypothesis, what is well visible on Figure 2. 


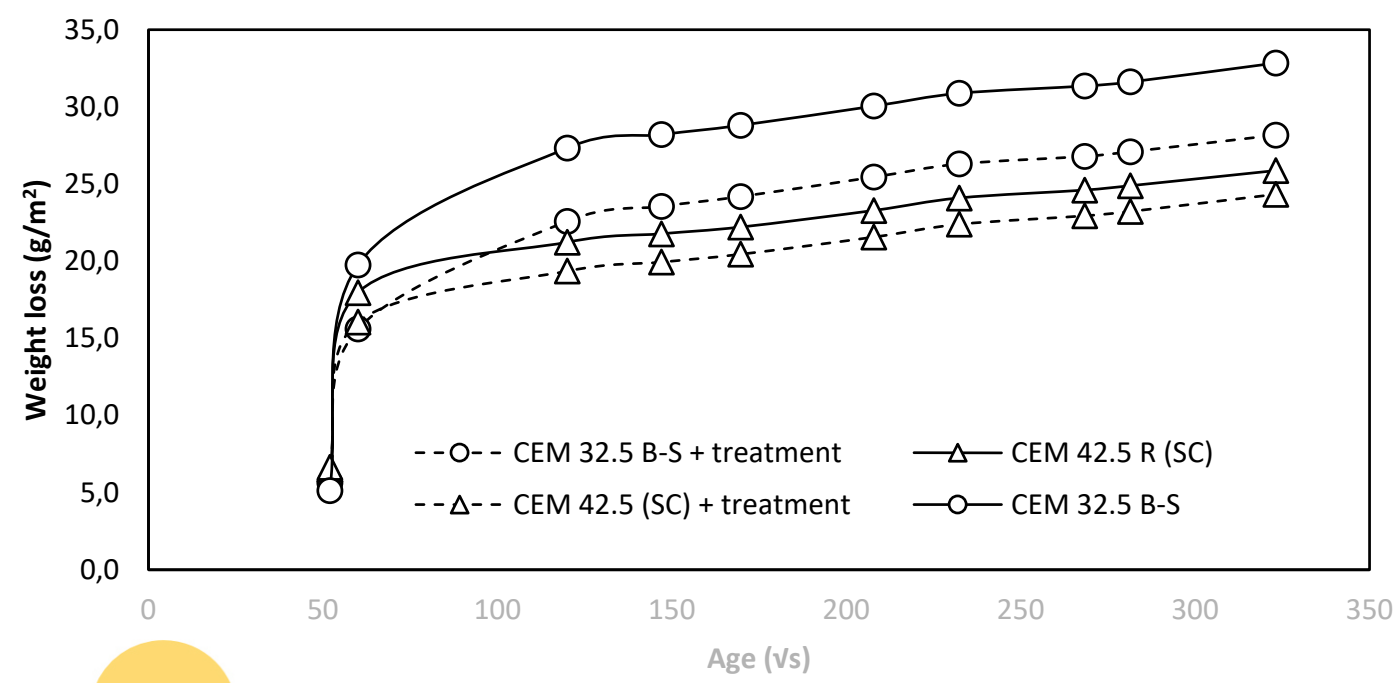

Figure 1. Monitored loss of the moisture in time.

Sudden change of the strain signalizes the moment of the rupture of mortar ring. The measurement of shrinkage declared, that mortar made of CEM I 42.5, which is specially prepared for transport

remaining set of sanp necessary to note, that

upper surface was expos

experiment declared, that in days.
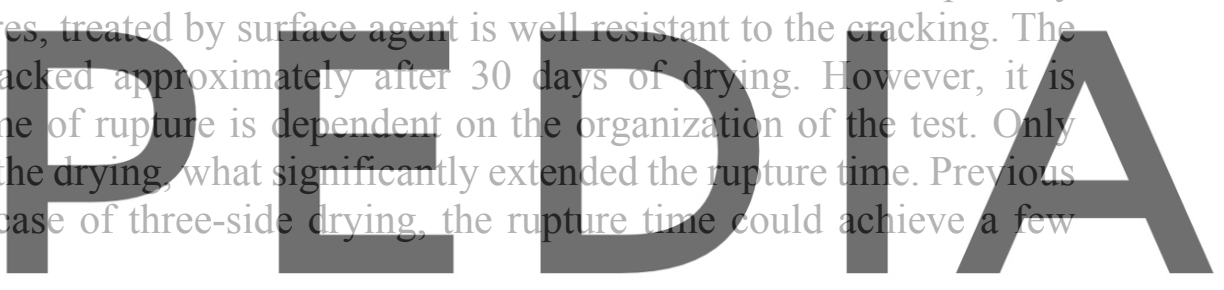

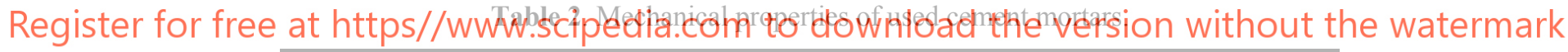

\begin{tabular}{ccc}
\hline Flexural strength $[\mathrm{MPa}]$ & CEM I 42.5 R $(\mathrm{SC})$ & CEM II 32.5 B-S \\
\hline 1 day & 2.9 & 1.8 \\
\hline 3 days & 8.1 & 2.7 \\
\hline 7 days & 9.7 & 5.7 \\
\hline 28 days & 9.8 & 9.5 \\
\hline Compressive strength $[\mathrm{MPa}]$ & & \\
\hline 1 day & 27.4 & 4.6 \\
\hline 3 days & 49.4 & 12.7 \\
\hline 7 days & 57.0 & 24.2 \\
\hline 28 days & 68.1 & 52.7 \\
\hline
\end{tabular}

Results of water adsorption test are shown in Figure 3, there is well visible an improvement of the impermeability due to applied surface treatment, used type of cement respectively. On the other hand, obtained differences in non-treated samples are very low, especially up to 15 minutes. Just this short-term water adsorption has significant sense in case of the durability. For both set of samples was the achieved level of improvement about $20 \%$. 


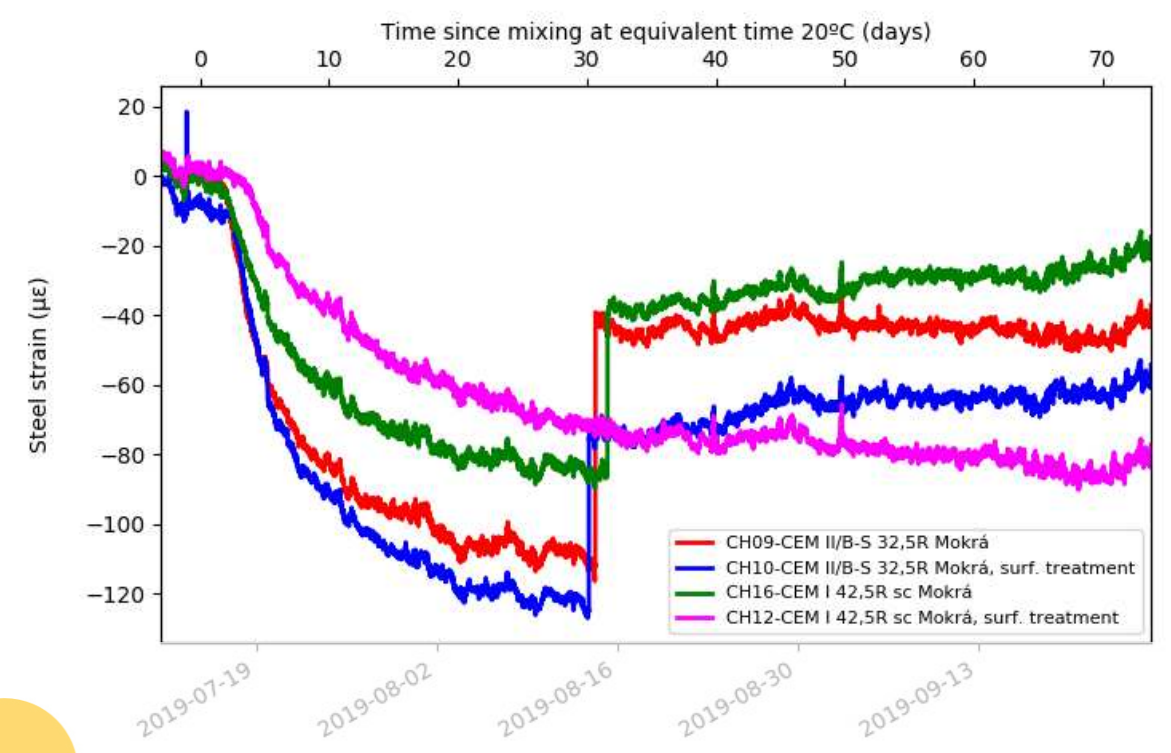

Figure 2. Results of the restrained shrinkage tests.

These results document the problem of concrete cracking during production of concrete pavement. Drying shrinkage, which is controlled by the diffusion, motivates to use binder with

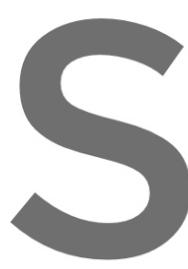
higher kinetics of hydration. On the other hand, higher kinetics contributes to the evolution of hydration heat and initial chernical shrinkage resulting in microcracks initiation. is necessary to balance both preventive intervention. During past years C was often used during production of concrete pavement, the motivation for type of cement was lower hydration kinetics, which po

However, number of cracks has occurred shortly after the casting. It was caused by increased

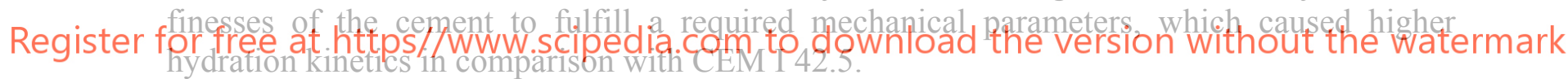

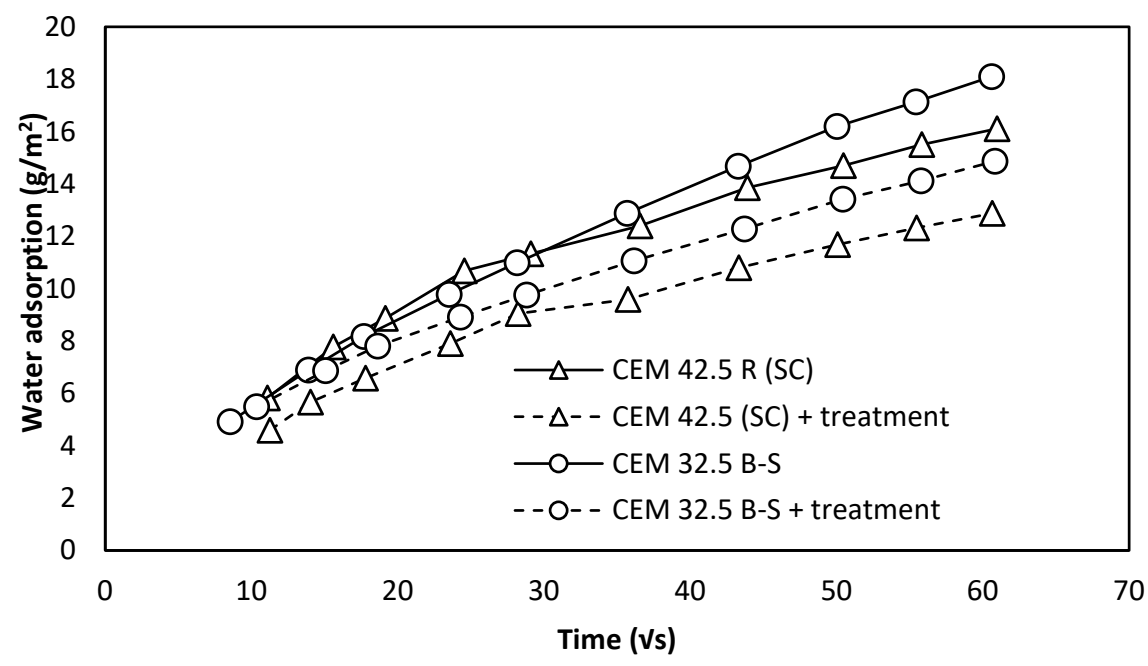

Figure 3. Results of water adsorption test. 


\section{Conclusions}

Performed experimental program was focused on the evaluation of the efficiency of surface treatment, which is applied to prevent sudden evaporation of the water and subsequent progress of cracks due to drying shrinkage. The program conducted on standard cement mortars declared, that blended binding systems are prone to loss of the moisture. In addition, blended cement exhibited higher tendency to cracking in terms of restrained shrinkage test, the studied surface treatment did not improve this property as well. Achieved results confirmed the improvement of water impermeability, however short-term water adsorption was nearly similar for all sets of samples, except of samples made from road cement, which were treated on their surface; they exhibited slightly lower permeability of the surface layer. Obtained results indicate suitability of Portland cement, which is produced for the specific application in transport concrete structures.

\section{Acknowledgements}

This research work was financially supported by project of over project COST No. LTC18063 and FV30062.

\section{ORCID}

Pavel Reiterman: https://orcid.org/0000-0002-3918-3647

Vendula Davidová: https://orcid.org/0000-0001-9727-6860

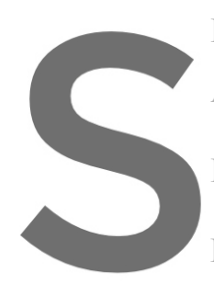

References

Aitcin, P. (2000). Cement doi: https://doi.org/10.1

Davidova, V. and Reiterman, to their hydration degre.

Deboucha, W., Leklou, N., K
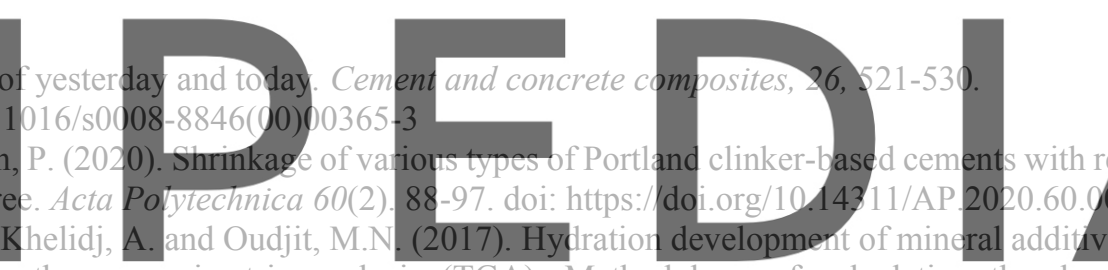
blended cement using thermogravimetric analysis (TGA): Methodology of calculating the degree of hydration. Construction and Building Materials, 146, 687-701.

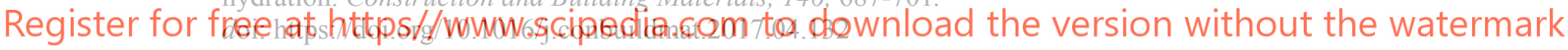

EN 196-1: Methods of testing cement - Part 1: Determination of strength, Czech Republic (2005).

Glinicki, M.A., Jaskulski, R. and Dabrowski, M. (2016). Design principles and testing of internal frost resistance of concrete for road structures - critical review. Roads and Bridges - Drogi i Mosty, 15, 21-43. doi: https://doi.org/10.7409/rabdim.016.002

Lothenbach, B., Scrivener, K. and Hooton, R.D. (2011). Supplementary cementitious materials. Cement and Concrete Research, 41.1244-1256. doi:https://doi.org/10.1016/j.cemconres.2010.12.001

Nili, M. and Ehsani, A. (2015). Investigating the effect of the cement paste and transition zone on strength development of concrete containing nanosilica and silica fume. Materials \& Design, 75, 174-183. Doi: https://doi.org/10.1016/j.matdes.2015.03.024

Reiterman, P., Holčapek, O., Zobal, O. and Keppert, M. (2019). Freeze-Thaw Resistance of Cement Screed with Various Supplementary Cementitious Materials. Reviews on advanced materials science, 58, 66-74. doi: https://doi.org/10.1515/rams-2019-0006

Vinkler, M. and Vítek, J.L. (2019). Drying and shrinkage of massive concrete wall segments-3 years experiment and analytical observations. Materials and Structures, 52. doi: https://doi.org/10.1617/s11527-019-1329-x 